\title{
Erratum to: Influence of short-term exposure to ultrafine and fine particles on systemic inflammation
}

\author{
Sabine Hertel · Anja Viehmann - Susanne Moebus - Klaus Mann - Martina Bröcker-Preuss • \\ Stefan Möhlenkamp • Michael Nonnemacher · Raimund Erbel · Hermann Jakobs • \\ Michael Memmesheimer · Karl-Heinz Jöckel • Barbara Hoffmann
}

Published online: 10 February 2011

(C) Springer Science+Business Media B.V. 2011

\section{Erratum to: Eur J Epidemiol (2010) 25:581-592 \\ DOI 10.1007/s10654-010-9477-x}

In the European Journal of Epidemiology 25(8) a printing error occurred in the manuscript concerning the unit of particle number concentration. The correct summary statistics of particle number concentrations $(\mathrm{PN})$ given in the text and in Table 2, p. 584 is $10^{4} / 1$ instead of $10^{4} / \mathrm{ml}$. Please find the revised Table 2. Since effect estimates of particle number were given per percent increase, results of the regression models in the text, tables and figures are correct as printed in the original publication.

The online version of the original article can be found under doi:10.1007/s10654-010-9477-x.

S. Hertel $(\bowtie) \cdot$ A. Viehmann $\cdot$ S. Moebus - M. Nonnemacher K.-H. Jöckel · B. Hoffmann Institute for Medical Informatics, Biometry and Epidemiology, University Hospital of Essen, Hufelandstr. 55, 45122 Essen, Germany

e-mail: sabine.hertel@uk-essen.de

H. Jakobs · M. Memmesheimer

Rhenish Institute for Environmental Research at the University

of Cologne, Cologne, Germany

S. Möhlenkamp · R. Erbel

West German Heart Centre of Essen, University

Duisburg- Essen, Duisburg, Essen, Germany

K. Mann · M. Bröcker-Preuss

Department of Endocrinology and Division of Laboratory

Research, University Hospital of Essen, Essen, Germany

S. Hertel

University of Duisburg-Essen, Duisburg, Essen, Germany 
Table 2 Summary statistics of hs-CRP, meteorological variables and air pollution concentrations for participants' residence on the day of blood draw (including also spatial and temporal distribution of PN)

\begin{tabular}{|c|c|c|c|c|c|c|c|c|c|}
\hline Variable & Mean & $\mathrm{SD}^{\mathrm{a}}$ & Min & 1st quartile & Median & 3rd quartile & Max & $\mathrm{IQR}^{\mathrm{b}}$ & $\mathrm{N}$ \\
\hline Mean daily temperature $\left({ }^{\circ} \mathrm{C}\right)$ & 10.56 & 7.74 & -11.23 & 5.22 & 10.89 & 16.39 & 29.23 & 11.17 & 3,999 \\
\hline Mean daily humidity (g/kg) & 6.5 & 2.6 & 1.3 & 4.6 & 6.2 & 8.3 & 14.2 & 3.7 & 3,999 \\
\hline $\mathrm{PM}_{2.5}\left(\mu \mathrm{g} / \mathrm{m}^{3}\right)$ & 17.23 & 10.81 & 3.54 & 10.12 & 14.55 & 21.61 & 187.10 & 11.50 & 3,999 \\
\hline $\mathrm{PM}_{10}\left(\mu \mathrm{g} / \mathrm{m}^{3}\right)$ & 21.44 & 12.85 & 3.82 & 12.84 & 18.45 & 26.74 & 246.00 & 13.90 & 3,999 \\
\hline $\mathrm{PN}\left(\times 10^{4} / 1\right)$ & 9,031 & 3,697 & 2,085 & 6,408 & 8,414 & 10,980 & 31,090 & 4,580 & 3,999 \\
\hline Spatial dist. of PN $\left(\times 10^{4} / 1\right)$ & 6,925 & 7,022 & 2,104 & 4,132 & 5,240 & 7,260 & 106,152 & 3,128 & 1,326 \\
\hline Temporal dist. of PN $\left(\times 10^{4} / 1\right)$ & 9,630 & 3,167 & 3,231 & 7,450 & 9,028 & 11,251 & 24,511 & 3,801 & 1,185 \\
\hline Hs-CRP (mg/l) & 3.0 & 5.2 & 0.1 & 0.7 & 1.5 & 3.2 & 84.4 & 2.5 & 3,999 \\
\hline
\end{tabular}

a Standard deviation

b Interquartile range 